Egyptian

Orthodontic Journal

\title{
SMILE ESTHETICS: ASSESSMENT OF PERCEIVED SMILE ATTRACTIVENESS AS RELATED TO DENTAL MIDLINE ASYMMETRY
}

\author{
Sahar Taher*, BDS, MSc, PhD
}

ABSTRACT:

Esthetics is of prime concern for dental professionals as well as lay people. Thus the aim of the current study was to highlight and broaden the conception of the influential impact of maxillary midline alterations on smile and dental attractiveness. The sample constituted a panel of sixty raters; twenty orthodontists, twenty dentists and twenty laypersons for rating smile attractiveness as perceived for a series of eleven images; one with no maxillary dental to facial midline discrepancy and another ten with varying amounts of dental midline shifts which were altered for a photograph of a female subject, aged 18 years old. $\mathcal{A}$ 10-point numerical rating scale was prepared and drawn on the evaluation form given to the sixty raters to assign a score for each image that best corresponded to the level of perceived smile attractiveness. The collected data was statistically analyzed for descriptive statistics including means and standard deviations for the assigned attractiveness rating scores. Moreover, one way analysis of variance test was computed to compare the mean scores assigned among the different raters. It was obvious that orthodontists and dentists were more intolerable to dental midline alterations than Caypersons with the orthodontists assigning lesser mean rating attractiveness scores than both dentists and laypersons. Meanwhile, a maxillary dental midline shift more than $3 \mathrm{~mm}$ was recognized as being unattractive by all raters which bear special consideration during orthodontic treatment to substantiate physical attractiveness and subsequent social interactions.

\footnotetext{
* Associate Professor of Orthodontics, Faculty of Oral and Dental Medicine, Cairo University.
} 
Egyptian

Orthodontic Journal

\section{INTRODUCTION}

Esthetics is a major concern for patients seeking orthodontic treatment as it affects greatly the facial and social attractiveness. Physical attractiveness is an important social issue and the face is one of its key features. The literature is enriched with data for assessment of factors affecting perception of facial ${ }^{1-3}$ and smile attractiveness. It has been emphasized that a smile is greatly influenced by the smile line and amount of gingival display ${ }^{4-10}$, harmony between arcs of curvature of the incisal edges of incisors and the lower lip ${ }^{11-13}$, buccal corridors ${ }^{14-19}$, midline coincidence ${ }^{4,20-26}$, tooth shape. ${ }^{4,7,27,28}$ and golden proportion ${ }^{29}$.

The dental midline asymmetry as one of the most important focal spots in the smile was considered by a number of authors. Beyer and Lindauer $(1998)^{20}$, investigated the importance of the maxillary midline position relative to the facial midline as a diagnostic feature. Altered images of two subjects were performed and the acceptability of midline deviations was assessed by a hundred and twenty personnel; orthodontists, general dentists, patients and parents of patients. An acceptable mean for dental midline shift up to $2.2+/-1.5 \mathrm{~mm}$ was reported. Moreover, orthodontists and dentists were more sensitive to midline shift than patients with the tolerance of parents in between.

Johnston et al. (1999) ${ }^{21}$, studied the influence of midline discrepancies on dental attractiveness ratings using a numerical scale from 1-10. It was found that attractiveness scores were less with discrepancies more than $2 \mathrm{~mm}$ between facial and dental midline. Discrepancies of $2 \mathrm{~mm}$ or more were noticed with $83 \%$ of the orthodontists and $56 \%$ of the lay people.

Kokich et al. (1999) 22 , compared the perception of dental professionals and lay people to altered dental esthetics. Orthodontists rated that a maxillary midline deviation of $4 \mathrm{~mm}$ was less esthetic than the others. However, lay people and general dentists were unable to detect even a $4 \mathrm{~mm}$ discrepancy.

Cardash et al. $(2003)^{23}$, observed the deviation of the facial and dental midline by using full facial photographs. Facial midline was determined by bisecting the distance between the medial angles of the 
eyes. Photographs were studied by ten observers; five general dentists and five lay people. It was noticed that the greater the deviation, the higher the detection rate particularly in more than $2 \mathrm{~mm}$ shifts.

Thomas et al. $(2003)^{24}$, studied the effect of axial midline angulations on the attractiveness of a smile. The influence of sex, direction of midline deviation and dominant hand on the evaluator's perception of dental esthetics was explored. Fifty orthodontists and fifty lay people evaluated these altered photographs by assigning both a numerical attractiveness rating and an acceptable or unacceptable rating to each picture. The results showed that attractiveness rating and acceptability ratings declined consistently as axial midline angulations increased. Discrepancies of 10 degrees were unacceptable by $68 \%$ of the orthodontists and $41 \%$ of the lay people.

Pinho et al. $(2007)^{25}$, investigated the impact of dental asymmetries on the perception of smile esthetics. Fifty raters of lay people, orthodontists and prosthodontists evaluated the original and altered photographs. Each rating was in accordance to a $100 \mathrm{~mm}$ visual analogue scale. Dental midline shift was perceived at $1 \mathrm{~mm}$ by orthodontists, at $3 \mathrm{~mm}$ by prosthodontists and lay people were unable to notice any midline shifts.

Khattab $(2008)^{26}$, determined the perception of maxillary midline shift as perceived by fifteen judges; five orthodontists, five dentists and five lay people. A visual analogue scale was used for rating of smile attractiveness where angular and linear midline shifts were altered in a series of photographs for male and female subjects. It was concluded that orthodontists and dentists were more sensitive to midline shifts than lay people, the direction of midline shift had no impact on perception of smile attractiveness and the perception of dental midline shift was not affected by gender of the volunteers.

Despite the great deal of data reported in the literature concerning the assessment of smile esthetics, the subjectivity of the perception for smile attractiveness usually keeps the gate opened for further investigation. Moreover, as long as dental midline asymmetries receive special attention in orthodontic diagnosis and treatment planning because orthodontists often treat patients with some degree of dental to facial midline 
discrepancies $^{21}$, it was found prudent to formulate a study in an attempt to broaden the understanding of the influential impact of maxillary dental midline shift on smile attractiveness as perceived by orthodontists, dentists and laypersons.

\section{MATERIALS AND METHODS}

\section{Sample}

The current study included a panel of sixty raters; twenty orthodontists, twenty dentists constituting a number of general practitioners and other dental specialists, as well as, twenty highly educated laypersons for rating the smile attractiveness. The age of all raters ranged from 30-45 years. Eleven smiling images; one with coincident maxillary dental to facial midlines and another ten with varying amounts of dental midline shifts were prepared by altering a photograph for a female subject, aged 18 years old for the rating process. The female subject was selected on the basis of having normal occlusion, normal smile line tooth relationship, no previous orthodontic treatment and no cosmetic treatment of the anterior teeth.

\section{Methods}

The captured photograph for the female subject was scanned to the computer system, where the facial midline was identified and constructed via a computer imaging software; Adobe Photoshop as shown in fig. (1A). Accordingly, the maxillary dental midline was altered to achieve various degrees of linear midline shifts where $0.5 \mathrm{~mm}$ was added progressively up to $5 \mathrm{~mm}$ forming ten images with different midline alterations to left side.

A series of eleven smiling images were grouped including the image with no dental midline shift, coded and set in a predetermined order only known by the investigator. Color printing was then carried out on glossy photo papers to be presented to the panel of raters as illustrated in fig. (1B,C and D). A 10-point numerical rating scale was prepared and drawn on the evaluation form given to the raters with the two ends of the scale assigned "Very unattractive" for point zero and "Very attractive" for point 10 as evident in fig.(2). For the rating process the sheet with the prearranged images was presented to the raters who were informed that 
they would be shown a series of varies smiling photographs for the same subject. Individually, each rater was requested to inspect every image and assign a score on the numerical rating scale that best corresponded to the level of smile perception experienced.
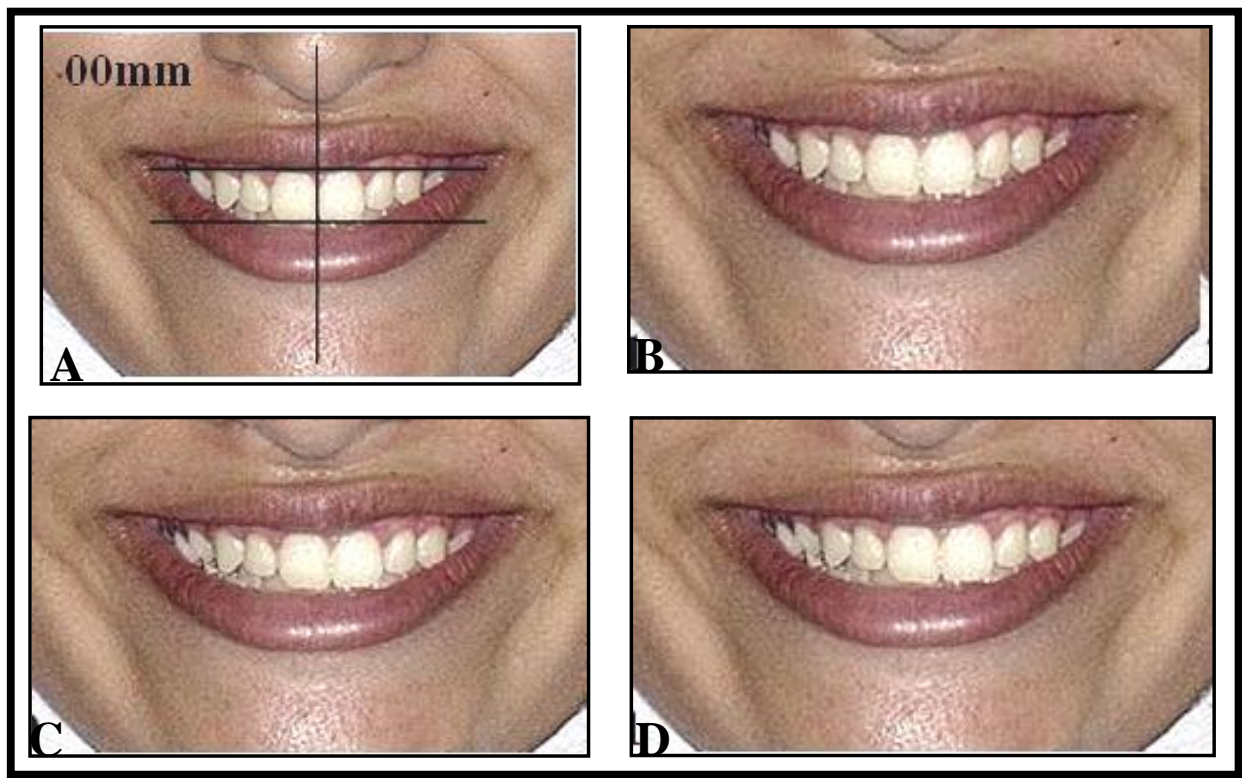

Fig. (1): Sample smiling images for the female subject with different manipulations of the maxillary dental midline. A, Image with coincident dental to facial midlines as constructed using a computer imaging software. B, Image with no dental midline shift as displayed to the raters. C, Altered image with $3 \mathrm{~mm}$ shift as displayed to the raters and D, Altered image with $5 \mathrm{~mm}$ shift as displayed to the raters.

Very unattractive

Very attractive

\begin{tabular}{|l|l|l|l|l|l|l|l|l|l|l|}
\hline 0 & 1 & 2 & 3 & 4 & 5 & 6 & 7 & 8 & 9 & 10 \\
\hline
\end{tabular}

Fig. (2): A 10-point numerical rating scale 
Egyptian

Orthodontic Journal

\section{Statistical analysis:}

The collected data was statistically analyzed for the following:

1- Descriptive statistics; means and standard deviations were calculated for ratings of different numeric scores assigned for the smile attractiveness at the various maxillary dental midline shifts.

2- One way analysis of variance (ANOVA) test was computed to reveal the significance of difference for mean rating scores among different raters.

\section{RESULTS}

Statistical analysis of the collected data is represented as follows:

1- Descriptive statistics of the collected numerical scores was computed to reveal the mean scores and standard deviations for perception of smile attractiveness at each level of maxillary dental midline shift as shown in table (I), figs.(3 and 4). The mean numerical scores decreased by increasing the maxillary dental midline shift as rated by the orthodontists, dentists and laypersons. For each dental midline shift the ratings assigned by the orthodontists were lower than those recorded by both dentists and laypersons. On the contrary, laypersons rated higher mean scores compared to both dentists and orthodontists, while ratings reported by dentists were intermediate between orthodontists and laypersons.

The highest mean scores were assigned by all raters for no midline shift in the form of 8.56, 9.20 and 9.51 for orthodontists, dentists and laypersons respectively. Meanwhile, at the least amount of maxillary midline shift; $0.5 \mathrm{~mm}$ the mean scores were 8.05 for orthodontists, 8.30 for dentists and 9.40 for laypersons. On the other hand, the least mean scores of $2.65,3.10$ and 3.55 were assigned by the different raters respectively for $5 \mathrm{~mm}$ midline shift.

2- Comparison of mean scores assigned by the different raters was computed using one way analysis of variance (ANOVA) as displayed in table (I). The significance level was set at $\mathrm{P} \leq 0.05$. No statistical significant difference was computed among the mean scores recorded by the different raters except at $0.5,1.5$ and $3 \mathrm{~mm}$ shifts. Mean scores assigned by both orthodontists and dentists significantly differed from those recorded by laypersons at $\mathrm{P} \leq 0.001$ for $0.5 \mathrm{~mm}$ shift and $\mathrm{P} \leq 0.05$ for both 1.5 and $3 \mathrm{~mm}$ shifts. 


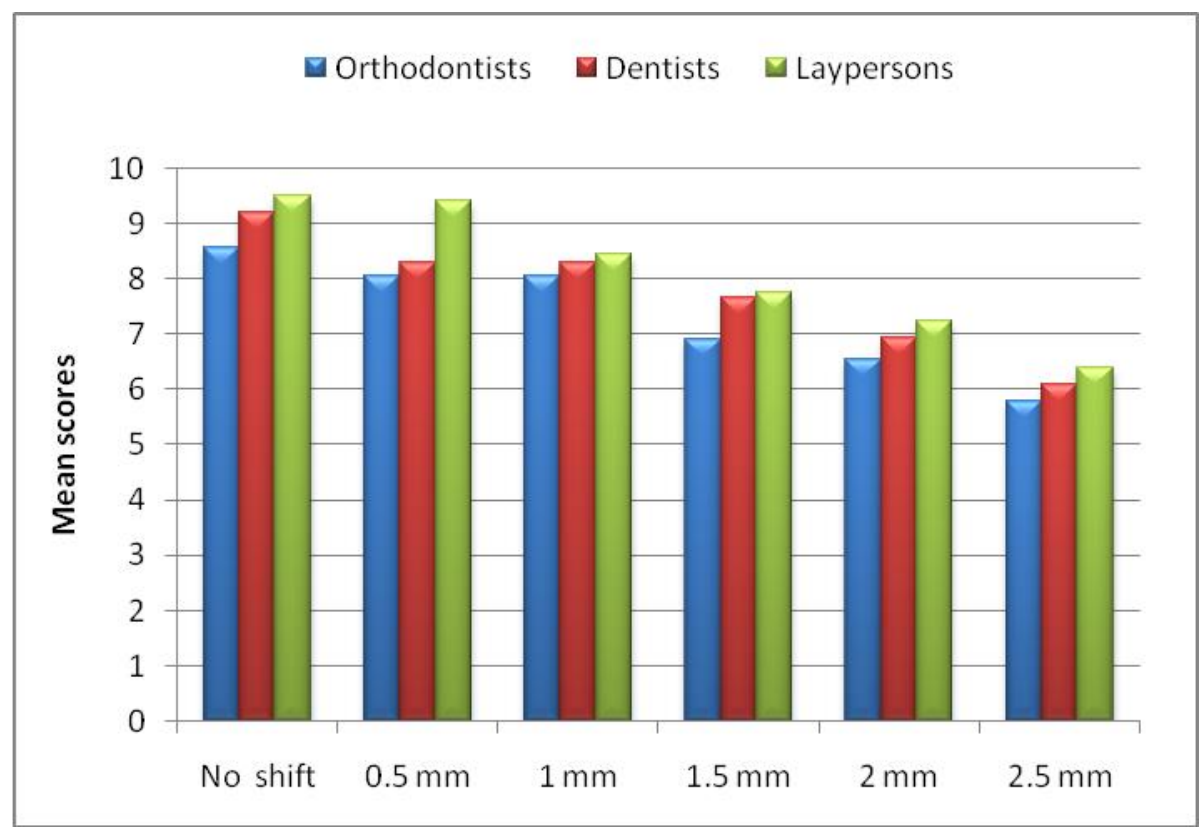

Fig. (3): A bar graph showing mean scores assigned by different raters for smile attractiveness as related to no maxillary dental midline shift to $2.5 \mathrm{~mm}$ shift.

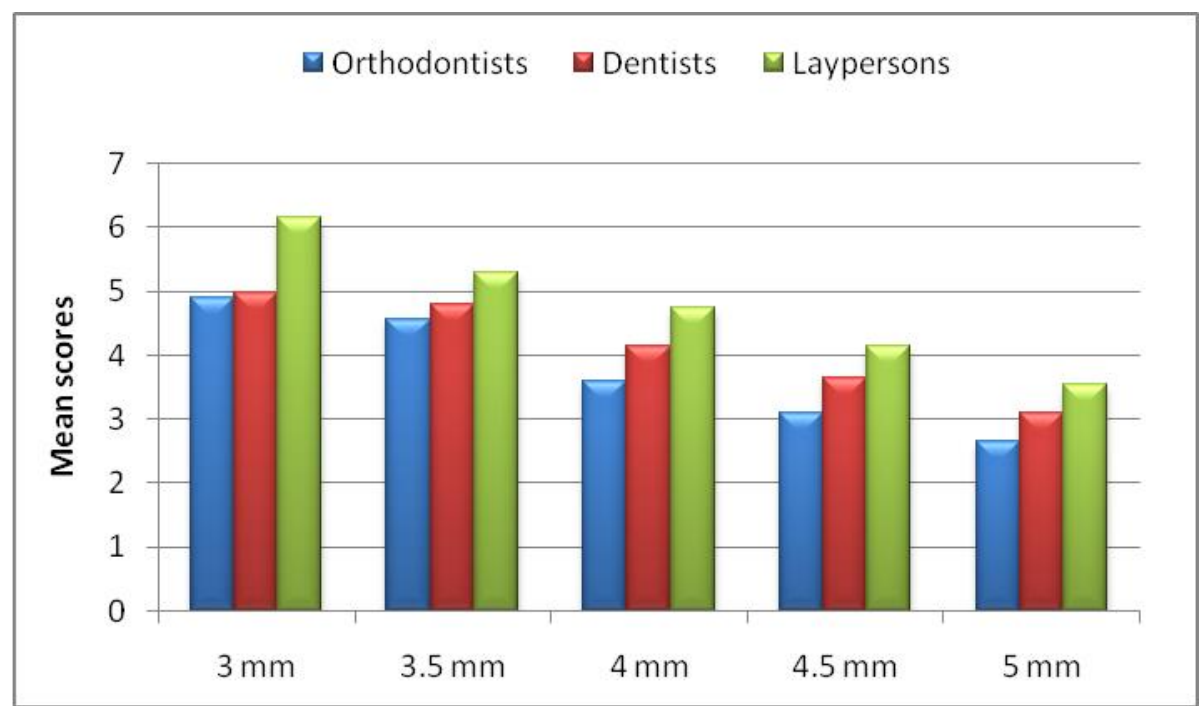

Fig. (4): A bar graph showing mean scores assigned by different raters for smile attractiveness as related to maxillary dental midline shifts of 3-5 mm. 
Egyptian

Orthodontic Journal

Table (I): Descriptive statistics and comparison of different mean scores assigned for smile attractiveness among different raters.

\begin{tabular}{|c|c|c|c|c|c|c|c|c|c|c|c|c|c|c|}
\hline \multirow{2}{*}{$\begin{array}{l}\text { Maxillary } \\
\text { dental } \\
\text { midline } \\
\text { alterations }\end{array}$} & \multicolumn{3}{|c|}{ O } & \multicolumn{3}{|c|}{ D } & \multicolumn{3}{|c|}{$\mathbf{L}$} & \multicolumn{2}{|c|}{ Anova } & \multicolumn{3}{|c|}{ Significance } \\
\hline & $\mathbf{N}$ & Mean & SD & $\mathbf{N}$ & Mean & SD & $\mathbf{N}$ & Mean & SD & $F$-value & $P$-value & O-D & O-L & D-L \\
\hline No shift & 20 & 8.56 & 1.92 & 20 & 9.20 & 1.16 & 20 & 9.51 & 1.82 & 0.671 & 0.621 & NS & NS & NS \\
\hline $0.5 \mathrm{~mm}$ & 20 & 8.05 & 2.12 & 20 & 8.30 & 0.68 & 20 & 9.40 & 0.46 & 9.492 & 0.0002 & NS & $* * *$ & $* * *$ \\
\hline $1 \mathrm{~mm}$ & 20 & 8.05 & 1.91 & 20 & 8.30 & 1.21 & 20 & 8.45 & 0.47 & 0.683 & 0.509 & NS & NS & NS \\
\hline $1.5 \mathrm{~mm}$ & 20 & 6.90 & 2.45 & 20 & 7.65 & 0.62 & 20 & 7.75 & 0.62 & 3.509 & 0.036 & NS & $*$ & $*$ \\
\hline $2 \mathrm{~mm}$ & 20 & 6.55 & 0.79 & 20 & 6.95 & 0.47 & 20 & 7.25 & 3.25 & 1.642 & 0.202 & NS & NS & NS \\
\hline $2.5 \mathrm{~mm}$ & 20 & 5.80 & 0.48 & 20 & 6.10 & 1.25 & 20 & 6.40 & 4.78 & 0.829 & 0.442 & NS & NS & NS \\
\hline $3 \mathrm{~mm}$ & 20 & 4.90 & 0.41 & 20 & 4.98 & 1.33 & 20 & 6.15 & 5.80 & 3.717 & 0.030 & NS & $*$ & $*$ \\
\hline $3.5 \mathrm{~mm}$ & 20 & 4.55 & 0.99 & 20 & 4.80 & 1.22 & 20 & 5.30 & 6.33 & 1.024 & 0.366 & NS & NS & NS \\
\hline $4 \mathrm{~mm}$ & 20 & 3.60 & 0.46 & 20 & 4.15 & 1.50 & 20 & 4.75 & 6.72 & 2.284 & 0.111 & NS & NS & NS \\
\hline $4.5 \mathrm{~mm}$ & 20 & 3.10 & 0.62 & 20 & 3.65 & 0.87 & 20 & 4.15 & 7.51 & 2.558 & 0.086 & NS & NS & NS \\
\hline $5 \mathrm{~mm}$ & 20 & 2.65 & 0.98 & 20 & 3.10 & 1.15 & 20 & 3.55 & 8.16 & 1.182 & 0.314 & NS & NS & NS \\
\hline
\end{tabular}

$\mathrm{N}$ : Number of raters

L: Laypersons

*: Significant at $\mathrm{P} \leq 0.05$
SD: Standard deviation

P: Probability

O: Orthodontists

D: Dentists

NS: No statistical significant difference $* * *$ : Significant at $\mathrm{P} \leq 0.001$

\section{DISCUSSION}

Assessment of dental appearance and its influential effect on smile esthetics should be considered during the evaluation of orthodontic treatment need and treatment outcome as esthetic improvement is the most frequently reported objective for seeking orthodontic treatment ${ }^{25,30}$. Dental maxillary midline symmetry gives the sense of unity and perfection which is considered the most important focal spot in the smile, thus the aim of the present study was formulated to assess the impact of dental midline alteration on smile attractiveness as perceived by a panel of different rater categories. 
Eleven images including an image with no maxillary dental to facial midline discrepancy were created for a female subject using a computer imaging software and prepared to be evaluated by the different rater categories. Similar applications were considered by Johnston et al. ${ }^{21}$, Kokich et al. ${ }^{22}$, as well as, Thomas et al. ${ }^{24}$ who used a photograph of a smiling woman altered by a computer software for assessment of the smile beauty. Moreover, it has been documented ${ }^{21}$ that changes in facial features other than the arrangement of the teeth might also affect dental attractiveness, so to minimize these possible confounding influences it was advised to use such approach of generating multiple images of the same person. In addition, it was intended to include one gender to substantiate the consistency of the results. This was in agreement with Thomas et al. ${ }^{24}$ who reported that the perceived dental attractiveness for female subjects were assigned both lower scores and a lower threshold of acceptability than did the male subjects. On the contrary, Kokich et al. ${ }^{7}$ found no significant difference in the perception of dental attractiveness for both genders.

The age of the selected female subject was within the adult stage, as recommended by Cardash et al. $^{23}$, as well as, Thomas et al. ${ }^{24}$. The increasing number of adults seeking orthodontic treatment for esthetic consideration dictated the preference of such developmental stage. Moreover, such age category assured full eruption of permanent dentition with the attainment of soft tissue growth including ultimate lip length particularly in females ${ }^{30}$, thus concealing any future effect on smile configuration and allowing to yield more consistent and reliable results. In addition, such age group guaranteed full assessment of normal occlusion criteria, thus allowing raters to concentrate attention on only one variable without being distracted to any other dental anomalies as advocated by Kokich et al. ${ }^{22}$. In contrast, Cardash et al. ${ }^{23}$ evaluated smile attractiveness in subjects undergoing treatment with different amounts of midline shifts. Such procedure was criticized for distracting the raters' attention with other types of malocclusion.

Despite the fact that the dental midline was altered in reference to the facial counterpart, full facial views were not proposed to the panel of raters. This was planned as the facial views could influence the perception 
of smile attractiveness. Similar regimen was suggested by Cardash et al. ${ }^{23}$ who reported that perception of midline shift in full facial views is problematic as raters would be distracted to other dentofacial configurations like facial form or hair color. More and above, it was advocated by Thomas et al. $^{24}$ that full facial photographs negatively affected the results for smile attractiveness since evaluation of dental midline position may be complicated if other midline facial structures were not well aligned as nose deviations.

Although previous studies ${ }^{24,26}$ considered angular and linear maxillary dental midline shifts for assessing dental attractiveness, only the linear shift was applied in the present study with a maximum alteration of $5 \mathrm{~mm}$ as an intermediate value between the different amounts of shifts reported in the literature. Cardash et al..$^{23}$ studied deviations up to $3 \mathrm{~mm}$, while Johnston et al. ${ }^{21}$ evaluated the perception of dental attractiveness up to $8 \mathrm{~mm}$ midline shift. Moreover, the incremental increase of $0.5 \mathrm{~mm}$ was followed in a trial to investigate the perception of any minute alteration of the maxillary dental midline, thus offering a chance to highlight the sensitivity of different categories of raters to deteriorated smile esthetics as related to dental midlineshift. In contrast Johnston et al. ${ }^{21}$ tested the perception of smile esthetics according to midline shifts of $2 \mathrm{~mm}$ incremental increase.

It has to be emphasized that although all dental midline alterations in the present study were performed to the left side as evident in fig.(1), no specific intention was underlying such choice for direction of shift. It was just to unify the direction of shift in all the altered images. The direction of shift whether to the right or to the left was stressed by several researchers $^{21,24,26}$ to have no impact on the perception of smile attractiveness.

Different categories of raters were included to allow comparison between dental professionals and laypersons in perception of smile attractiveness. Moreover, this permitted the distinction in the level of sensitivity for perception of different categories for dental midline shift, which is a goal of concern in orthodontic treatment. Distinguishing the perception of orthodontists in particular from laypersons highlighted the formulation of the maxillary midline shifts that could be present at the end 
of orthodontic treatment and still not perceived as being unattractive to the public thus surpassing any social communication problems. Such regimen for choosing raters was stressed by Kokich et al. ${ }^{22}$ who declared that perception of professionals and laypersons for smile esthetics differed significantly.

One of the interesting views intended in the current study was the application of a numerical rating scale for scoring of perceived smile attractiveness. Curiosity to differentiate results based on data collected from a different rating scale other than the most widely used visual analogue scales reported in the literature $e^{2,3,17,26}$ was one of the factors in evoking the idea of the current study. A numerical rating scale offers a rapid, simple and easily comprehendible method for rating that allows computing of mean rating scores which decrease variability among judges. Similarly, Johnston et al. ${ }^{21}$ used such 10-point numerical scale and emphasized that it simply allowed judges to express their perception of the relative attractiveness of any of the images in a consistent way. On the other hand, despite that the application of visual analogue scales was claimed to avoid bias toward preferred values and also to allow yielding mean quantitative data ${ }^{31}$, it was criticized for the inequality of the responses produced on rating and raters might use different portions of the scale and ignore others particularly the extremes.

Findings of the present study revealed that as the maxillary dental midline shift increased, the mean attractiveness rating scores decreased. In addition, orthodontists assigned lesser mean rating scores than both dentists and laypersons which seemed to indicate their greater sensitivity to dental midline alterations. This was consistent with most of the reported data in the literature ${ }^{20-22,26}$, despite that a different rating scale was applied.

Regarding the comparison among different categories of raters, generally, the statistical significant difference reported was confined to the orthodontists and dentists on one hand against laypersons on the other hand. On the contrary, both orthodontists and dentists showed no significant difference in the mean rating scores for all amounts of maxillary dental midline alterations. This was in disagreement with the results of Kokich et al. ${ }^{22}$, as well as, Khattab ${ }^{26}$ who revealed that dental 
Egyptian

Orthodontic Journal

attractiveness ratings of orthodontists significantly differed from dentists. The possible reasons for such disagreement might be related to the different number of raters or type of rating scale.

It was apparent that orthodontists and dentists were found to be more sensitive to maxillary dental midline alterations than lay persons even at very mild levels of shifts as evident by the significant difference between dentists and orthodontists with respect to laypersons at $0.5 \mathrm{~mm}$ shift as tabulated in table (I). Moreover, such significant difference which reflected the variation in smile attractiveness ratings was highlighted at $3 \mathrm{~mm}$ shift or less. On the other hand, at dental midline alterations more than $3 \mathrm{~mm}$, no statistically significant difference was noticed among all raters reflecting comparable perception for the deterioration of smile esthetics. Such findings were in agreement to Beyer and Lindauer ${ }^{20}$, as well as, Johnston et $\mathrm{al}^{21}$. In contrast, Kokich et $\mathrm{al}^{22}$, declared that the orthodontists rated a maxillary midline deviation of $4 \mathrm{~mm}$ as less esthetic than the others, while dentists and lay people were unable to detect even a $4 \mathrm{~mm}$ deviation.

An interesting observation in the results of the present study was that although no significant difference for mean rating scores was manifested among raters at midline shifts greater than $3 \mathrm{~mm}$, the standard deviations related to the relevant mean scores of laypersons compared to those of orthodontists and dentists was high as evident in table (I). This could be explained on the basis of apparent fluctuation in individual rating scores assigned by laypersons reflecting the variability for perception of smile attractiveness among non-professionals. In contrast, such findings demonstrated the consistency of the individual scoring data recorded by the orthodontists which again seemed to confirm the higher sensitivity and comparable attractiveness ratings assigned by orthodontists to alterations of the maxillary dental midline.

\section{CONCLUSIONS}

From the results of the present study the following conclusions could be drawn:

1- Orthodontists and dentists were more intolerable to maxillary dental midline alterations than laypersons. 
Egyptian

Orthodontic Journal

2- Orthodontists assigned lower smile attractiveness rating scores than both dentists and laypersons by increasing the maxillary dental midline shifts.

3- Maxillary dental midline shifts more than $3 \mathrm{~mm}$ were perceived as being unattractive by all rater categories; orthodontists, dentists and laypersons.

\section{Clinical Implications:}

In spite of the fact that beauty is in the eye of the beholder and no actual standardized scale could be used for measuring smile esthetics, but clinically, it is of great importance to estimate to what limit the dental to facial midline discrepancy is acceptable and unlikely to adversely affect dentofacial attractiveness. This study revealed that by virtue of their experience, orthodontists are more sensitive to alterations in dental appearance than the general public. However, orthodontists have to consider patients' esthetic expectations when planning treatment and the esthetic ratings awarded by lay people should not be overlooked as it influences their social interactions.

\section{REFERENCES}

1- Karavaka S, Halazonetis D, Spyropoulos M. Configuration of facial features subjective evaluation of facial type. Am J Orthod Dentofac Orthop 2008; 133:2-6.

2- Kiekens RMA, Kuijpers-Jagtman AM, Van 't Hof MA, Van 't Hof BE, Straatman H, Maltha JC. Facial esthetics in adolescents and its relationship to "ideal" ratios and angles. Am J Orthod Dentofac Orthop. 2008; 133:188.e1- 188.e8.

3- Lim H, Ko KT, Hwang H. Esthetic impact of premolar extraction and nonextraction treatments on Korean borderline patients. Am J Orthod Dentofac Orthop. 2008; 133:524-31.

5- Tjan AH, Miller GD. Some esthetic factors in smile. J Prosth Dent 1984; 51:24-28.

6- Dong JK, Jin TH, Cho HW, Oh SC. The esthetics of the smile: a review of some recent studies. Int J Prosth. 1999; 12:9-19. 
7- Geron S, Atalia W. Influence of sex on the perception of oral and smile esthetics with different gingival display and incisal plane inclination. Angle Orthod. 2004; 7:778-784.

8- Kokich VO, Kokich VG, Kiyak HA. Perceptions of dental professionals and laypersons to altered dental esthetics: asymmetric and symmetric situations. Am J Orthod Dentofac Orthop. 2006; 130:141-151.

9- Jornung F, Fardal T. Perceptions of patients' smiles. A comparison of patients' and dentists' opinions. Am Dent Assoc. 2007; 138:6-22.

10-9-Van der Geld P, Oosterveld P,Van Heck G, Kuijpers -Jagtman AM. Smile attractiveness. Self-perception and influence on personality. Angle Orthod. 2007; 77:759-765.

11- Van der Geld PA, Oosterveld P, Van Waas MA, Kuijpers-Jagtman AM. Digital videographic measurement of tooth display and lip position in smiling and speech: reliability and clinical application. Am J Orthod Dentofac Orthop. 2007; 3:301-307.

12-Blitz N. Criteria for success in creating beautiful smiles. Oral Health. 1997; 2:38-42.

13- Sarver DM. The importance of incisor positioning in the esthetic smile: The smile arc. Am J Orthod Dentofac Orthop. 2001; 120:134-142.

14- Maulik C, Nanda R. Dynamic smile analysis in young adults. Am J Orthod Dentofac Orthop. 2007; 132:307-315.

15- Dunn WJ, Murchison DF, Broome JC. Esthetics: patients' perceptions of dental attractiveness. J Prosth. 1996; 5:166-171.

16-Moore T, Southard KA, Casko JS, Qian F, Southard TE. Buccal corridors and smile esthetics. Am J Orthod Dentofac Orthop. 2005; 127:528-529.

17- Parekh S, Fields H, Beck M, Rosenstiel S. Attracriveness of variations in the smile arc and buccal corridor space as judged by orthodontists and lay men. Angle Orthod. 2005; 76:557-563. 
18-Ritter DE, Gandini LG, Pinto Ados S, Locks A. Esthetic influence of negative space in the buccal corridor during smiling. Angle Orthod. 2005; 76:198-203.

19-Roden-Johnson DR, Gallerano R, English J. The effects of buccal corridor spaces and arch form on smile esthetics. Am J Orthod Dentofac Orthop. 2005; 127:343-350.

20-Krishnana V, Daniel ST, Lazar D, Asok A. Characterization of posed smile by using visual analogue scale, smile arc, buccal corridor measures, and modified smile index. Am J Orthod Dentofac Orthop. 2008; 133:515-523.

22-Beyer JW, Lindauer SJ. Evaluation of the dental midline position. Semin Orthod. 1998; 4:145-152.

23-Johnston CD, Burden DJ, Stevenson MR. The influence of dental to facial midline discrepancy on dental attractiveness ratings. Eur J Orthod. $1999 ; 21: 517-522$.

24- Kokich VO, Kiyak HA, Shapiro PA. Comparing the perception of dentists and lay people in altered esthetics. J Esthet Dent 1999; 11:311-324.

25-Cardash HS, Ormanier Z, Laufer BZ. Observable deviation of the facial and anterior teeth midlines. J Prosth Dent 2003; 89:282-285.

26- Thomas JL, Hyes C, Zawaideh S. The effect of axial midline angulations on dental esthetics. Angle Orthod. 2003; 73:359-364.

27- Pinho B, Ciriaco N, Faber M, Lenza H. Impact of dental asymmetries on the perception of smile esthetics. Am J Orthod Dentofac Orthop. 2007; 132:6-12.

28- Khattab SM. Influence of dental midline shift on the perception of smile attractiveness. Master Thesis, Cairo University, 2008.

29- Anderson KW, Behrents RG, McKinney C, Buschangd PH. Tooth shape preferences in an esthetic smile. Am J Orthod Dentofac Orthop. $2005 ; 128: 458-465$. 
Egyptian

Orthodontic Journal

30- Wolfart S, Thormann H, Freitag S, Kern M. Assessment of dental appearance following chin incisor proportions. Am J Orthod Dentofac Orthop. 2005;113:159-165.

31-Proffit WR, Fields HW, Sarver DM. Contemporary Orthodontics. $4^{\text {th }}$ ed., St. Louis: Mosby 2007; p189-192.

32-Bishara SE, Jakobson JR, Hessin TJ, Treder JE. Soft tissue profile changes from 5 to 45 years of age. Am J Orthod Dentofac Orthop. 1998;114:698-706.

33- Shaw WC, Rees G, Dawe M, Charles CR.The influence of the dentofacial appearance on the social attractiveness of young adults. Am J Orthod Dentofac Orthop. 1985; 87:21-26. 